\title{
Are Family Physicians Appropriately Screening for Postpartum Depression?
}

\author{
MAJ Dean A. Seehusen, MC, USA, Laura-Mae Baldwin, MD, MPH, \\ LTC Guy P. Runkle, MC, USA, and LTC Gary Clark, MC, USA
}

Purpose: Despite the availability of screening tools for postpartum depression (PPD), there is a general consensus that the condition is underdiagnosed. This study was conducted to determine how frequently family physicians screen for PPD, what methods they use to screen, and what influences their screening frequency.

Methods: A survey of members of the Washington Academy of Family Physicians was conducted. Three hundred sixty-two (60.9\%) mailed surveys were returned. The 298 physicians who saw postpartum women and children younger than 1 year of age were included in the study.

Results: Of the study population, $70.2 \%$ always or often screened for PPD at postpartum gynecologic examinations, and $46 \%$ always or often screened mothers at well-child visits. Of those who screened, $30.6 \%$ reported using a validated screening tool. of those, only $18 \%$ used a tool specifically designed to screen for PPD. Logistic regression modeling showed that female sex [odds ratio $(O R)=2.2$ ], training in PPD during residency $(O R=8.1)$, training in PPD through medical literature $(O R=2.1)$, and agreement that postpartum depression is common enough to warrant screening $(O R=1.9)$ were all significantly associated with more frequent screening at postpartum gynecologic visits. Agreement that screening takes too much effort was associated with less frequent screening $(\mathrm{OR}=0.8)$.

Conclusions: Although family physicians believe that PPD is serious, identifiable, and treatable; screening is not universal and use of screening tools designed for PPD is uncommon. Training in postpartum depression and female sex are the variables most strongly associated with frequent screening. (J Am Board Fam Pract 2005;18:104-12.)

Although pregnancy-related psychiatric conditions have been described since antiquity, these conditions have received relatively little attention until recently. ${ }^{1}$ Postpartum depression (PPD) develops in $10 \%$ to $20 \%$ of women in the first 6 months after delivery. $^{2}$ The rate may be more than $25 \%$ in

Submitted, revised, 22 November 2004.

From the Department of Family and Community Medicine, Eisenhower Army Medical Center, Fort Gordon, Georgia (DAS), Department of Family Medicine, University of Washington, Seattle (L-MB), and Department of Family Practice, Madigan Army Medical Center, Tacoma. Address correspondence to MAJ Dean A. Seehusen, MC, USA, Department of Family and Community Medicine, Eisenhower Army Medical Center, Bldg 300, Fort Gordon, GA 30905 (E-mail: dseehusen@msn.com).

These results were originally published as a Thesis for Master's Degree in Public Health at the University of Washington. It was presented as an extended paper at the North American Primary Care Research Group's 2004 Annual Meeting; 2004 Oct 10-13; Orlando, Florida.

The views presented here are those of the authors and do not reflect official policy of Madigan Army Medical Center, the Department of the Army, or the United States Government. women that have had a previous episode of PPD. ${ }^{3}$ More than half of all women who develop postpartum depression will still be suffering symptoms a year later. ${ }^{4}$

The entire family is impacted by PPD. Fathers are more prone to develop depression in the postpartum period if their wives develop PPD. ${ }^{5}$ The marital relationship is significantly stressed by the occurrence of postpartum depression. ${ }^{6}$ Children of depressed mothers more commonly develop conduct and attention disorders. ${ }^{7}$ They also suffer from both social and cognitive delays up to age 4 and perhaps beyond. ${ }^{8}$ Murray et $\mathrm{al}^{9}$ found difficulties in maternal-child interaction and behavioral problems both at home and at school in 5-year-old children whose mothers had suffered from postpartum depression. Sharp et $\mathrm{a}^{10}$ found delayed intellectual development among 4 year-old male children of mothers with postpartum depression.

The diagnostic criteria for PPD are the same as for major depression except that the episode starts 
during the postpartum period. Routine use of any screening tool results in increased recognition of postpartum depression. A few quick and easy-toadminister tools have been developed to screen for PPD. ${ }^{11,12}$ To make the diagnosis, a more thorough evaluation is completed once a patient screens positive on one of these tools.

The Edinburgh Postnatal Depression Scale ${ }^{13}$ is the most studied postpartum depression screening tool and has been shown to be highly effective at detecting PPD with few false positives or false negatives. One Australian study found this scale to have a sensitivity of $100 \%$ and a specificity of $95.5 \%$. Georgiopoulos et $\mathrm{al}^{14}$ found that routine administration of the Edinburgh Postnatal Depression Scale increased the rate of diagnosis of PPD from $3.7 \%$ to $10.7 \%$ at community postnatal care sites in Minnesota.

Despite the availability of effective screening tools, postpartum depression remains highly underdiagnosed in the United States ${ }^{1,14}$ and elsewhere. ${ }^{15,16}$ One possible reason that universal screening is not conducted may be a general lack of awareness that screening tools exist. Even when clinicians are aware of reliable tools, many may be reluctant to use them for fear that the process will be time-consuming and expensive. Another potential reason for the lack of screening is uncertainty about how to treat women with high scores on a screening tool, ${ }^{17}$ including a generalized concern about using medication in women who are breastfeeding.

The United States Preventive Services Task Force endorses screening for depression in the general population. ${ }^{18}$ Many authors have called for routine screening of postpartum women. ${ }^{7,19-22}$ This study was conducted to determine how frequently Washington state family physicians screen postpartum women at routine postpartum gynecologic examinations and mothers at well-child visits. It explores family physicians' beliefs, attitudes, and feelings concerning postpartum depression and which screening tools they use. Finally, this study was designed to identify factors associated with increased screening frequency.

\section{Methods}

This cross-sectional study used a systematic approach to sample Washington state family physicians. Permission to conduct this study was re- quested from, and granted by, the University of Washington Institutional Review Board.

\section{Study Population}

A list of active physicians of the Washington Academy of Family Physicians was purchased. The list was ordered numerically by zip code and alphabetically within individual zip codes. Every third member was assigned to the study population.

\section{Questionnaire}

A 25-item questionnaire was developed to investigate subjects' postpartum screening habits, beliefs, and attitudes regarding postpartum depression and perceptions about their patient populations. Many of the questions were based on surveys conducted by St. John ${ }^{23}$ and LaRocco. ${ }^{24}$ The survey gathered demographic data, information about practice settings, and sources from which subjects had received formal training in postpartum depression. The frequency with which physicians screened for postpartum depression was measured using a 4-point Likert scale (never, sometimes, often, or always). Attitudes and beliefs about postpartum depression were measured with a 5 -point Likert scale that asked for a level of agreement with declarative statements.

The questionnaire was pilot tested on family physicians to ensure face validity before the start of the project. The questionnaire was mailed to the study population along with a cover letter explaining the study and a stamped return envelope in October 2003. Confidentiality of respondents was maintained through a coded number method. Two follow-up letters with replacement surveys were sent to nonresponders at 1 -month intervals.

\section{Analysis}

Statistical analysis was done with SPSS version 11 (SPSS Inc.,Chicago, IL). Simple frequencies of physician demographics, practice characteristics, training, and beliefs about PPD were used to describe the study respondents. Responses to belief statements were dichotomized by combining "agree" and "strongly agree" into "agreed" and other responses into "did not agree." Differences in screening frequency by physician demographics, practice characteristics, training, and beliefs were compared using $\chi^{2}$ analysis. Screening frequency was dichotomized into "never or sometimes" and 
"often or always" to ensure adequate numbers of respondents in each group.

Multiple logistic regression was used to identify factors independently associated with frequency of screening during postnatal gynecologic and wellchild visits. Variables that were significantly related to screening frequency in bivariate analysis were grouped into 3 categories: demographics, training, and beliefs. These variables were entered into regression models in different order to identify relationships between the variables and screening frequency. Model 1 entered training variables into the regression model first, followed by belief variables, followed by demographic variables. Model 2 entered demographic variables first, followed by belief variables and then training variables. Model 3 entered demographic variables, then training variables, then belief variables. After all variables were entered, nonsignificant variables were removed stepwise until all remaining variables had a significance of $P<.10$ or less.

\section{Results}

Of 594 questionnaires sent, 362 (60.9\%) were returned. Of the respondents, 335 saw patients at least 10 hours per week, our definition of an actively practicing physician. Of these, 310 (92.5\%) saw postpartum women in their practices, 303 $(90.4 \%)$ saw children under 1 year of age, and 298 $(89.0 \%)$ saw both. The results were similar in all 3 of these subgroups, and only those 298 who saw both were included in the study sample.

The study sample had slightly more men than women and averaged 44 years of age (Table 1). The study participants mostly worked in group practices and had been out of residency for an average of 12 years. No physicians in the study sample were currently resident physicians, and $2.4 \%$ were not residency graduates.

Table 1. Demographic Characteristics of Study Group

\begin{tabular}{lc}
\hline Characteristic (responses) & $\begin{array}{c}\text { Percentage } \\
\text { or Average (SD) }\end{array}$ \\
\hline Male $(\mathrm{n}=294)$ & $57.1 \%$ \\
Age $(\mathrm{n}=293)$ & $44.0(7.3)$ \\
Years since graduating residency $(\mathrm{n}=288)$ & $12.0(7.8)$ \\
Practice setting $(\mathrm{n}=287)$ & \\
Group & $82.9 \%$ \\
Solo & $7.3 \%$ \\
Other & $9.8 \%$ \\
\hline
\end{tabular}

Thirty-one percent of the study physicians always screened, and another $40 \%$ often screened for postpartum depression at routine postpartum gynecologic visits. Only 5.7\% never screened postpartum women. Thirteen percent of physicians always screened, $33 \%$ often screened, and $15.2 \%$ never screened mothers at well child visits.

Of the 271 valid responses from physicians who screened at least sometimes, 83 (30.6\%) responded that they used a validated screening tool. Of those who reported using a validated tool, a standardized clinical interview was by far the most popular, being used by $82 \%$ of those who screen. The Beck Depression Inventory was the most popular questionnaire-type tool. Twenty-nine percent of those who screened used the Beck, $10 \%$ used the Edinburgh Postnatal Depression Scale, $8 \%$ used the Zung Depression Scale, and 8\% used the Postpartum Depression Checklist.

Most respondents had received formal training on postpartum depression in a variety of venues. Residency training was the most commonly listed source of training, in which $89.5 \%$ of respondents had been taught about postpartum depression. Two thirds or more had received training in each of the following ways: in medical school, through the medical literature, and through continuing medical education conferences.

In general, postpartum depression was recognized as a common, serious, and treatable disease (Table 2). Screening for postpartum depression was felt to be effective at both the postpartum visit and well-child visits by most respondents. There was less confidence about the ease of routine screening. Almost 20\% of respondents agreed with the statement, "screening at every postpartum visit would take too much effort," whereas more than half disagreed or strongly disagreed with the statement. Almost 35\% agreed with the statement, "screening at every well child visit up to 1 year of age would take too much effort."

\section{Bivariate Analysis}

Sex, residency training in PPD, medical literature training in PPD, age, and years since graduating from residency were all significantly associated with frequent screening at postpartum visits (Table 3), In addition, belief that PPD is common enough to warrant screening and belief that postpartum depression is serious enough to warrant screening were both associated with more frequent screening. 
Table 2. Family Physician Beliefs about Postpartum Depression Screening

\begin{tabular}{lc}
\hline Statement (responses) & Agree (\%) \\
\hline $\begin{array}{l}\text { General beliefs about postpartum depression } \\
\text { 1. Therapy for postpartum depression is } \\
\text { effective. }(\mathrm{n}=294)\end{array}$ & 94.9 \\
2. Postpartum depression affects the children of & 97.6 \\
$\quad$ affected mothers. $(\mathrm{n}=296)$ & \\
3. Postpartum depression affects the spouses of & 99.0 \\
$\quad$ affected women. $(\mathrm{n}=296)$ & \\
General beliefs about screening for postpartum & \\
$\quad$ depression & \\
1. Postpartum depression is common enough to \\
$\quad$ warrant screening. (n $=295)$
\end{tabular}

Disagreement that screening takes too much effort was also associated with more frequent screening at postpartum visits (Table 4).

Frequency of screening at well-child visits was significantly associated with sex, residency training, CME training, medical literature training, and years since graduating residency (Table 3), Belief that postpartum depression is common enough to warrant screening and belief that PPD is serious enough to warrant screening were both associated with more frequent screening at well-child visits. Belief that PPD screening takes too much effort and that it would not be effective were both associated with less frequent screening at well-child visits (Table 4). Practice setting and formal training on postpartum depression in medical school were not significantly associated with frequency of screening in either setting.

\section{Multivariate Analysis}

After controlling for other variables in the model, being female, training in PPD during residency, training in PPD through medical literature, agreement that postpartum depression is common enough to warrant screening, and disagreement that screening takes too much effort were all significantly associated with more frequent screening at postpartum gynecologic visits. All logistic regression models used produced similar results (Table 5). When logistic regression modeling was performed for variables associated with frequent screening at well-child visits, similar results were found, with the exception that female sex approached, but did not reach, statistical significance.

\section{Discussion}

It takes an average of 17 years after new medical knowledge has been generated in clinical trials to become incorporated into clinical practice. ${ }^{25}$ The Edinburgh Postnatal Depression Scale was developed in $1987 .{ }^{13}$ It is now approaching the time when widespread application of this tool would be expected.

Despite repeated calls to action in the medical literature, screening for postpartum depression among family physicians in Washington state is not yet universal. When screening is done, it is uncommonly done with a validated tool that was designed specifically for the detection of postpartum depression (ie, the Edinburgh Postnatal Depression Scale or the Postpartum Depression Checklist). These tools are considered to be superior to other depression screening tools because they avoid evaluating symptoms that are common to both depression and the normal postpartum state, such as sleep disturbance. The majority of respondents were screening at postpartum gynecologic visits but not at wellchild visits. This represents many missed opportunities for screening as family physicians perform over $18 \%$ of well-child examinations nationwide. ${ }^{26}$ They also perform over $10 \%$ of all prenatal visits, ${ }^{27}$ suggesting a comparable proportion of postpartum visits completed by family physicians. A significant proportion of women suffering from postpartum depression may never be diagnosed as a result

General depression screening tools were popular methods of screening in this population. Many of these tools have been used in research on PPD. ${ }^{28}$ Use of these tools is certainly better than no screening at all. The most popular method of screening identified in this study was use of a structured clinical interview. This survey did not attempt to determine the content of the structured clinical interview used by physicians. There is a validated 2-question method that asks one question 
Table 3. Frequency of Screening for Postpartum Depression by Family Physician Demographics, Practice Setting, and Training Characteristics

\begin{tabular}{|c|c|c|c|c|}
\hline $\begin{array}{l}\text { Population (Number of } \\
\text { Respondents*) }\end{array}$ & $\begin{array}{c}\text { Often or Always Screen } \\
\text { Women at Postpartum Visits }\end{array}$ & $\begin{array}{c}P \\
\text { value }^{+}\end{array}$ & $\begin{array}{c}\text { Often or Always Screen } \\
\text { Mothers at Well-Child Visits }\end{array}$ & $\begin{array}{c}P \\
\text { value } \\
\end{array}$ \\
\hline Total $(\mathrm{n}=298)$ & $70.2 \%$ & & $46.0 \%$ & \\
\hline \multicolumn{5}{|l|}{ Demographics } \\
\hline \multicolumn{5}{|l|}{ Gender } \\
\hline Women $(\mathrm{n}=125,126)$ & $78.4 \%$ & .011 & $54.8 \%$ & .011 \\
\hline $\operatorname{Men}(\mathrm{n}=167,166)$ & $64.7 \%$ & & $39.8 \%$ & \\
\hline \multicolumn{5}{|l|}{ Age } \\
\hline$<38(\mathrm{n}=69)$ & $81.2 \%$ & .004 & $47.8 \%$ & $\mathrm{NS}^{\ddagger}$ \\
\hline $38-44(\mathrm{n}=80)$ & $78.8 \%$ & & $48.8 \%$ & \\
\hline $45-49(\mathrm{n}=66)$ & $62.1 \%$ & & $47.0 \%$ & \\
\hline$>49(\mathrm{n}=76)$ & $59.2 \%$ & & $40.8 \%$ & \\
\hline \multicolumn{5}{|l|}{ Practice setting } \\
\hline Solo $(\mathrm{n}=21)$ & $57.1 \%$ & NS & $47.6 \%$ & NS \\
\hline Group $(\mathrm{n}=236,237)$ & $72.0 \%$ & & $46.0 \%$ & \\
\hline Other $(\mathrm{n}=28,27)$ & $67.9 \%$ & & $48.1 \%$ & \\
\hline \multicolumn{5}{|l|}{ Training in PPD } \\
\hline \multicolumn{5}{|l|}{ Medical School } \\
\hline Yes $(\mathrm{n}=200,199)$ & $72.0 \%$ & NS & $47.7 \%$ & NS \\
\hline No $(\mathrm{n}=91,92)$ & $67.0 \%$ & & $42.4 \%$ & \\
\hline \multicolumn{5}{|l|}{ Residency } \\
\hline Yes $(\mathrm{n}=261)$ & $74.7 \%$ & $<.001$ & $48.3 \%$ & .042 \\
\hline No $(\mathrm{n}=31)$ & $35.5 \%$ & & $29.0 \%$ & \\
\hline \multicolumn{5}{|l|}{ CME conferences } \\
\hline Yes $(\mathrm{n}=194,193)$ & $74.2 \%$ & NS & $51.3 \%$ & .015 \\
\hline No $(\mathrm{n}=94,99)$ & $63.3 \%$ & & $36.4 \%$ & \\
\hline \multicolumn{5}{|l|}{ Medical Literature } \\
\hline Yes $(n=205)$ & $75.1 \%$ & .008 & $51.7 \%$ & . 004 \\
\hline No $(\mathrm{n}=87)$ & $59.8 \%$ & & $33.3 \%$ & \\
\hline
\end{tabular}

* If 2 numbers are shown, they represent postpartum visits and well-child visits, respectively.

+ Significance determined using $\chi^{2}$ analysis.

${ }^{\ddagger}$ NS, not significant; PPD, postpartum depression; CME, continuing medical education.

about feeling of depression and another about anhedonia. The literature reports that this method is $97 \%$ sensitive and $67 \%$ specific $^{29}$ for major depression in the general population and is considered a reasonable screening method for postpartum depression. ${ }^{3}$ On the other hand, a guided interview using a mnemonic such as "A SAD FACES" has been used for general depression. ${ }^{30}$ More research needs to be done to determine the types of structured clinical interviews that are being used by physicians to screen for postpartum depression and how useful these tools are in this clinical setting.

The predictors of screening frequency found in this study help explain the lack of universal screening by validated methods. It is clear that the problem is not a sense of apathy about the disease or a lack of confidence in treatment efficacy. More than $90 \%$ of respondents agreed that family physicians should screen for postpartum depression, that postpartum depression is serious enough to warrant screening, and that treatment is effective. However, a significant proportion of respondents believed that screening takes too much effort. Increasing pressure for productivity and lack of compensation may make screening a low priority for family physicians in the current work environment. Beliefs about the burden of screening for depression have previously been shown to significantly influence physician's perceptions about the importance of screening for depression in the general population. $^{31}$

Washington family physicians are receiving training on postpartum depression from a wide variety of sources. Most received some training on the topic in residency and medical school. Medical 


\begin{tabular}{|c|c|c|c|c|}
\hline Statement (responses*) & $\begin{array}{l}\text { Often or Always } \\
\text { Screen Women } \\
\text { at Postpartum Visits }\end{array}$ & $\begin{array}{c}P \\
\text { value }\end{array}$ & $\begin{array}{l}\text { Often or Always } \\
\text { Screen Mothers } \\
\text { at Well-Child Visits }\end{array}$ & $\begin{array}{c}P \\
\text { value }\end{array}$ \\
\hline \multicolumn{5}{|c|}{ General beliefs about postpartum depression } \\
\hline \multicolumn{5}{|c|}{$\begin{array}{l}\text { 1. Postpartum depression affects the children of affected } \\
\text { mothers. }\end{array}$} \\
\hline Agreed $(\mathrm{n}=287)$ & $70.4 \%$ & $\mathrm{NS}^{\dagger}$ & $46.7 \%$ & $\mathrm{NS}^{\dagger}$ \\
\hline Did Not Agree $(\mathrm{n}=7)$ & $71.4 \%$ & & $28.6 \%$ & \\
\hline \multicolumn{5}{|c|}{$\begin{array}{l}\text { 2. Postpartum depression affects the spouses of affected } \\
\text { women. }\end{array}$} \\
\hline Agreed $(n=291)$ & $70.8 \%$ & $\mathrm{NS}^{\dagger}$ & $46.4 \%$ & $\mathrm{NS}^{\dagger}$ \\
\hline Did Not Agree $(\mathrm{n}=3)$ & $33.3 \%$ & & $33.3 \%$ & \\
\hline \multicolumn{5}{|c|}{ 3. Therapy for postpartum depression is effective. } \\
\hline Agreed $(\mathrm{n}=277)$ & $70.8 \%$ & $\mathrm{NS}^{\dagger}$ & $46.6 \%$ & $\mathrm{NS}^{\dagger}$ \\
\hline Did Not Agree $(\mathrm{n}=15)$ & $66.7 \%$ & & $40.0 \%$ & \\
\hline \multicolumn{5}{|c|}{ General beliefs about screening for postpartum depression } \\
\hline \multicolumn{5}{|c|}{$\begin{array}{l}\text { 1. Postpartum depression is common enough to warrant } \\
\text { screening. }\end{array}$} \\
\hline Agreed $(\mathrm{n}=256)$ & $77.7 \%$ & $<.001^{\ddagger}$ & $50.8 \%$ & $<.001^{\ddagger}$ \\
\hline Did Not Agree $(\mathrm{n}=37)$ & $18.9 \%$ & & $13.5 \%$ & \\
\hline \multicolumn{5}{|c|}{$\begin{array}{l}\text { 2. Postpartum depression is a serious enough problem to } \\
\text { warrant screening. }\end{array}$} \\
\hline Agreed $(n=264)$ & $73.9 \%$ & $<.001^{\ddagger}$ & $48.5 \%$ & $.013^{\ddagger}$ \\
\hline Did Not Agree $(\mathrm{n}=29)$ & $37.9 \%$ & & $24.1 \%$ & \\
\hline \multicolumn{5}{|c|}{ Beliefs about screening women at postpartum visits } \\
\hline \multicolumn{5}{|c|}{$\begin{array}{l}\text { 1. Screening at every postpartum visit would take too much } \\
\text { effort. }\end{array}$} \\
\hline Agreed $(\mathrm{n}=56)$ & $48.2 \%$ & $<.001^{\ddagger}$ & $21.4 \%$ & $<.001^{\ddagger}$ \\
\hline Did Not Agree $(\mathrm{n}=234)$ & $76.1 \%$ & & $52.1 \%$ & \\
\hline \multicolumn{5}{|c|}{ 2. Screening at every postpartum visit would not be effective. } \\
\hline Agreed $(\mathrm{n}=10,21)$ & $50.0 \%$ & $\mathrm{NS}^{+}$ & $20.0 \%$ & $\mathrm{NS}^{\dagger}$ \\
\hline Did Not Agree $(\mathrm{n}=281,268)$ & $71.2 \%$ & & $47.0 \%$ & \\
\hline \multicolumn{5}{|c|}{ Beliefs about screening mothers at well-child visits } \\
\hline \multicolumn{5}{|c|}{$\begin{array}{l}\text { 1. Screening at every well-child visit up to one year-of-age } \\
\text { would take too much effort. }\end{array}$} \\
\hline Agreed $(\mathrm{n}=102,103)$ & $60.8 \%$ & $.009^{\ddagger}$ & $26.2 \%$ & $<.001^{\ddagger}$ \\
\hline Did Not Agree $(\mathrm{n}=191,190)$ & $75.4 \%$ & & $56.8 \%$ & \\
\hline \multicolumn{5}{|c|}{ 2. Screening at every well-child visit would not be effective. } \\
\hline Agreed $(\mathrm{n}=21)$ & $71.4 \%$ & & $23.8 \%$ & $.034^{\ddagger}$ \\
\hline Did Not Agree $(\mathrm{n}=268)$ & $70.5 \%$ & $\mathrm{NS}^{\ddagger}$ & $47.8 \%$ & \\
\hline
\end{tabular}

* If two numbers are shown, they represent postpartum visits and well-child visits, respectively.

+ Statistical analysis based on Fisher's exact test.

₹ Statistical analysis based on $\chi^{2}$ analysis.

school training seems to have little influence on screening practices, whereas other educational settings seem to be highly influential. It is interesting that residency training was far more predictive of screening at postpartum gynecologic than at wellchild visits. This may be because the idea of screening at well-child visits is relatively new and may not yet have been incorporated into residency training programs. $^{32,33}$
Recent graduates are more likely to frequently screen for postpartum depression at routine postpartum gynecologic examinations than are family physicians who have been practicing for a long time. Several factors may have influenced this finding. The disease is more recognized as a serious, common, and treatable problem today than in the past. The advent of selective serotonin-reuptake inhibitors, with their excellent safety profile and 
Table 5. Multivariate Analysis: Odds of More Frequent Screening by Family Physicians with Different Demographic, Training Characteristics, and Beliefs

\begin{tabular}{|c|c|c|c|}
\hline & $\mathrm{OR}^{*}$ & $95 \% \mathrm{CI}$ & $P$ Value \\
\hline \multicolumn{4}{|c|}{ Screening for PPD always or often at postpartum gynecologic visits } \\
\hline Sex (female) & 2.2 & $1.1-4.2$ & .02 \\
\hline Residency training in PPD (yes) & 8.1 & $3.3-20.0$ & $<.000$ \\
\hline Medical literature training in PPD (yes) & 2.1 & $1.1-4.0$ & .022 \\
\hline PPD is common enough to warrant screening (agreed) & 1.9 & $1.5-2.4$ & $<.000$ \\
\hline $\begin{array}{l}\text { Screening for PPD at every postpartum visit would take } \\
\text { too much effort (agreed) }\end{array}$ & 0.8 & $0.7-1.0$ & .039 \\
\hline \multicolumn{4}{|l|}{ Screening mothers for PPD always or often at well-child visits } \\
\hline Sex (female) & 1.6 & $1.0-2.8$ & .065 \\
\hline Residency training in PPD (yes) & 2.7 & $1.1-6.5$ & .030 \\
\hline Medical literature training in PPD (yes) & 2.4 & $1.4-4.3$ & .002 \\
\hline PPD is common enough to warrant screening (agreed) & 1.5 & $1.1-1.9$ & .003 \\
\hline $\begin{array}{l}\text { Screening for PPD at every well-child visit would take } \\
\text { too much effort (agreed) }\end{array}$ & 0.7 & $0.6-0.8$ & $<.000$ \\
\hline
\end{tabular}

* OR, odds ratio adjusted for other variables in the model; CI, confidence interval; PPD, postpartum depression.

${ }^{\dagger}$ All variables with significance of $P<.1$ were left in each model.

compatibility with breast-feeding, has made treatment easier than in the past. ${ }^{34}$ These changes have probably resulted in a greater emphasis on PPD in residency training. PPD has also received more attention in both the medical literature and the lay press in recent years.

In this population of family physicians, women physicians were more likely to screen for postpartum depression on a regular basis than were men. Much of this difference was associated with the younger age and more recent training of women family physicians. However, the sex difference persisted after controlling for training and beliefs about PPD. One explanatory hypothesis for this sex difference is that female physicians are better able to empathize with the postpartum patient and therefore better able to understand the complications of that period. This is supported by the Gunn et $\mathrm{al}^{15}$ study of general practitioners in Australia, which found that women practitioners were much more likely to ask about women's feelings at postpartum visits. In addition, there is evidence that women physicians screen women more frequently for other female conditions, such as breast and cervical cancer, than do male physicians. ${ }^{35-37}$ Lurie et $\mathrm{al}^{38}$ found that physician's beliefs contributed to the increased rate of female cancer screening. Further research on this sex difference in screening practices is needed.

Selection bias is a possible weakness of the current study. The respondents were chosen from members of the Washington Academy of Family Practice. It is possible that members of such professional societies are more likely to be aware of and follow recommendations for screening. Thus, this study could have overestimated the actual frequency of screening for postpartum depression. The Washington Academy of Family Physicians estimates that well over $90 \%$ of the State's family physicians are members of the Academy, however.

Another possible source of bias is that physicians who are frequent screeners for postpartum depression were more likely than others to respond. This possibility is supported by the fact more than $40 \%$ of respondents were women and the average age was 44 . Only $37 \%$ of the entire WAFP are women and the average age of members is 50 (Karla Pratt, personal communication, 2004 Nov 2). Less than one third of living graduates of family practice residencies in the United States are female. ${ }^{39}$ This suggests that women and younger physicians responded disproportionately to this survey. Again, this would have led to an overestimation of screening rates. It is not certain that family physicians in Washington are representative of family physicians in other regions of America or other countries. Further studies would need to be done to determine to what extent these findings can be generalized. Finally, this study may be subject to recall bias because the findings are based on self-reported rates of screening rather than a chart review or direct observation. 
This study also did not address why some physicians only screened some patients or how physicians approached the diagnostic workup once a patient had a positive screening examination. These areas require further research to understand all the reasons postpartum depression is being underdiagnosed.

\section{Conclusions}

Although the family physicians in this study believed that postpartum depression was serious, identifiable, and treatable, screening was not universal, and use of screening tools designed for postpartum depression was uncommon. It seems that training physicians in residency and through the medical literature are effective means of increasing the frequency of screening. Efforts should be made to incorporate postpartum depression training into all family medicine residency curricula. These curricula should emphasize that postpartum depression is common and provide experience in the use of easy, validated screening tools. In addition, efforts should be made to identify ways to decrease the burden that is perceived by physicians to accompany widespread screening. Future research should identify the most efficient and effective screening and treatment methods to help physicians overcome barriers to screening and ensure that the many women who will develop postpartum depression are identified and treated.

\section{References}

1. Spinelli M. Antepartum and postpartum depression. J Gen Spec Med 1998;1:33-6.

2. Miller L. Postpartum depression. JAMA 2002;287: 762-5.

3. Wisner K, Parry B, Piontek C. Postpartum depression. N Engl J Med 2002;347:194-9.

4. Clay E, Seehusen D. A review of postpartum depression for the primary care physician. South Med J 2004;97:157-61.

5. Areias ME, Kumar R, Barros H, Figueiredo E. Correlates of postnatal depression in mothers and fathers. Br J Psychiatry 1996;169:36-41.

6. Wrate RM, Rooney AC, Thomas PF, Cox JL. Postnatal depression and child development. A three-year follow-up study. Br J Psychiatry 1985;146:622-7.

7. Seidman D. Postpartum psychiatric illness: the role of the pediatrician. Pediatr Rev 1998;19:128-31.

8. Cogill S, Caplan H, Alexandra H, Robson K, Kumar R. Impact of maternal postnatal depression on cognitive development of young children. BMJ 1986; 292:1165-7.
9. Murray L, Sinclair D, Cooper P, Ducournau P, Turner P, Stein A. The socioemotional development of 5-year-old children of postnatally depressed mothers. J Child Psychol Psychiatry 1999;40:125971.

10. Sharp D, Hay D, Pawlby S, Schmucker G, Allen H, Kumar R. The impact of postnatal depression on boys' intellectual development. J Child Psychol Psychiatry 1995;36:1315-36.

11. Sharp LK, Lipsky MS. Screening for depression across the lifespan: a review of measures for use in primary care settings. Am Fam Physician 2002;66: 1001-8.

12. Beck CT. Screening methods for postpartum depression. J Obstet Gynecol Neonatal Nurs 1995;24: 308-12.

13. Cox J, Holden J, Sagovsky R. Detection of postnatal depression: development of the 10-item Edinburgh postnatal depression scale. Br J Psychiatry 1987;150: 782-6.

14. Georgiopoulos A, Bryan T, Wollan P, Yawn B. Routine screening for postpartum depression. J Fam Pract 2001;50:117-22.

15. Gunn J, Lumley J, Yound D. The role of the general practitioner in postnatal care: a survey from Australian general practice. Br J Gen Pract 1998;48:1570-4.

16. Bagedahl-Strindlund M, Monsen Borjesson K. Postnatal depression: a hidden illness. Acta Psychiatr Scand 1998;98:272-5.

17. Richards J. Postnatal depression is not being missed in primary care. BMJ 1998;317:1658.

18. US Preventive Services Task Force. Screening for depression: recommendations and rationale. Ann Intern Med 2002;136:760-4.

19. Cooper P, Murray L. Postnatal depression. BMJ 1998;316:1884-6.

20. Sinclair D, Murray L. Effects of postnatal depression on children's adjustment to school. Teacher's reports. Br J Psychiatry 1998;172:58-63.

21. Georgiopoulos A, Bryan T, Yawn B, Houston M, Rummans T, Therneau T. Population-based screening for postpartum depression. Obstet Gynecol 1999;93:653-7.

22. Susman J. Postpartum depressive disorders. J Fam Pract 1996;43:S17-S24.

23. St. John J. Identifying postpartum depression in primary care pediatrics: a survey of current practice patterns, beliefs, and consideration of routine screening. Seattle: University of Washington Health Services Department; 1999.

24. LaRocco A. Identifying depression in Ob-Gyn practice: a survey of $\mathrm{Ob}-\mathrm{Gyns}$ regarding their attitudes and practices related to routine depression screening. Health Services Department. Seattle: University of Washington Health Services Department; 2001.

25. Committee on Quality of Health Care in America, Institute of Medicine. Crossing the quality chasm: a 
new health system for the 21 st century. Washington DC: National Academy Press; 2001.

26. The Robert Graham Center. Family physicians increase provision of well-infant care despite decline in prenatal services [monograph on the Internet]. Washington DC: The Robert Graham Center; 2002 [Cited 2002 Nov 8]. Available from http://www.grahamcenter.org/x390.xml.

27. The Robert Graham Center. Family physicians' declining contribution to prenatal care in the united states [monograph on the Internet]. Washington DC: The Robert Graham Center; 2002 [Cited 2002 Nov 8]. Available from http://www.graham-center. org/x387.xml.

28. Chaudron L, Klein M, Reminton P, Palta M, Allen C, Essex M. Predictors, prodromes and incidence of postpartum depression. J Psychosom Obstet Gynaecol 2001;22:103-12.

29. Arroll B, Khin N, Kerse N. Screening for depression in primary care with two verbally asked questions: cross sectional study. BMJ 2003;327:1144-6.

30. Montano C. Recognition and treatment of depression in a primary care setting. J Clin Psychiatry 1994;55 Suppl:18-34.

31. Main D, Lutz L, Barrett J, Matthew J, Miller R. The role of primary care clinician attitudes, beliefs, and training in the diagnosis and treatment of depression. Arch Fam Med 1993;2:1061-6.

32. Zimmer K, Minkovitz C. Maternal depression: an old problem that merits increased recognition by child healthcare providers. Curr Opin Pediatr 2003; 15:636-40.

33. McLennan J, Offord D. Should postpartum depression be targeted to improve child mental health? J Am Acad Child Adolesc Psychiatry 2002;41:28-35.

34. Gupta S, Masand P, Rangwani S. Selective serotonin reuptake inhibitors in pregnancy and lactation. $\mathrm{Ob}$ Gyn Survey 1998;53:733-6.

35. Franks P, Clancy C. Physician gender bias in clinical decision making. Screening for cancer in primary care. Med Care 1992;31:213-8.

36. Osborn E, Bird J, McPhee S, Rodnick J, Fordham D. Cancer screening by primary care physicians: can we explain the difference?. J Fam Pract 1991;32:465-71.

37. Lurie N, Slator J, McGovern P, Ekstrum J, Quam L, Margolis K. Prevention care for women: does the sex of the physician matter? N Engl J Med 1993;329: 478-82.

38. Lurie N, Margolis K, McGovern P, Mink P, Slator J. Why do patients of female physicians have higher rates of breast and cervical cancer screening? J Gen Intern Med 1997;12:34-43.

39. American Academy of Family Physicians [homepage on the Internet]. Shawnee Mission (KS): American Academy of Family Physicians; c2004 [updated 2004 Jan 1; cited 2004 Nov 1]. Living graduates of family practice residency programs by selected characteristics 1969-2003; [about 3 screens]. Available from: http://www.aafp.org/x761.xml. 